\title{
Cloning and functional analysis of the chitinase gene promoter in peanut
}

\author{
X.L. Chen*, R.T. Song*, M.Y. Yu, J.M. Sui, J.S. Wang and L.X. Qiao \\ Key Lab of Plant Biotechnology in Universities of Shandong Province, \\ Qingdao Key Lab of Germplasm Innovation and Application of Major Crops, \\ College of Life Science, Qingdao Agricultural University, \\ Qingdao, Shandong, China \\ ${ }^{*}$ These authors contributed equally to this study. \\ Corresponding author: L.X. Qiao \\ E-mail: Ixqiao73@163.com
}

Genet. Mol. Res. 14 (4): 12710-12722 (2015)

Received April 10, 2015

Accepted July 2, 2015

Published October 19, 2015

DOI http://dx.doi.org/10.4238/2015.October.19.15

ABSTRACT. Chitinase is an important pathogenesis-related protein in plants, and it can accumulate when induced by salicylic acid (SA) or other elicitors. Here, we found that chitinase mRNA levels were 4.5-times greater when peanut seedlings were sprayed with $1.5 \mathrm{mM} \mathrm{SA}$, as compared to water. The upstream promoter sequence of the chitinase gene was cloned by TAIL-PCR and the potential cis-regulatory elements in this promoter were predicted by the cis-element databases PLACE and plantCARE. Elements in the promoter related to SA induction and disease resistance response included AS-1, GT1-motif, GRWAAW, TGTCA, W-box, and WB-box. The full-length promoter $(P)$ and a series of 5 '-deleted promoters $\left(P_{1}-P_{5}\right)$ were cloned and then substituted for the 35 S promoter of $p$ CAMBIA1301-xyIA, which carries the xylose isomerase gene as the selectable marker and GUS as the reporter gene. Six plant expression vectors ( $p C A M B I A 1301-$ $\left.x y|A-P-p C A M B I A 1301-x y| A-P_{5}\right)$ were obtained. The six expression vectors were then transferred into onion epidermal cells and peanut plants by Agrobacterium-mediated transformation. Both the full-length and deleted promoters resulted in GUS staining of the onion epidermis cells when 
induced by SA. In onion epidermis cells, GUS enzyme activity was greater after SA induction. In transgenic peanut plants, GUS mRNA levels were greater after SA induction. Consideration of the cis-regulatory elements predicted by PLACE and plantCARE suggested that AS-1, GRWAAW, and W-box are positive regulatory elements in $P_{2}$ and $P_{3}$ and that GT1-motif and TGTCA are negative regulatory elements between $P$ and $P_{2}$.

Key words: Peanut (Arachis hypogaea L.); Chitinase gene; SA induction; Inducible promoter; Deletion analysis

\section{INTRODUCTION}

Peanut plants are often attacked by pathogens that cause diseases such as mesh spot, leaf spot, black rot, rust, and bacterial wilt. These diseases reduce seed quality and yield; unfortunately, peanut germplasm resources with high resistance to disease are rare (Wang and Zhang, 2013). One solution to this lack of resistance in peanut germplasm is to transfer exogenous resistance genes into peanuts. Such transgenic peanut plants could defend themselves against pathogens through production of a variety of hydrolytic enzymes and pathogenesis-related proteins (PR proteins) (Vellicce et al., 2006; Jia et al., 2011). Chitinase is one of the proteins of interest in this context, as it is a PR protein that has a role in plant defense responses against fungal pathogens (Kellmann et al., 1996; Liu et al., 2007). Production of chitinase can be induced in plants by inoculation with pathogenic fungi and by exogenous application of salicylic acid (SA) (Kellmann et al., 1996; Qu et al., 2008).

The successful creation of transgenic plants with the required level and pattern of expression of the transferred exogenous gene is largely determined by the gene promoter sequences, which are important transcription regulatory elements. Constitutive expression promoters such as cauliflower mosaic virus 35 S promoter (CaMV35S) and rice actin gene promoter (Actin1) have been widely used to drive the expression of transferred exogenous genes in all tissues and at all developmental stages of transgenic plants. The sustained expression of foreign genes, however, can suppress plant growth and development and can cause the accumulation of toxic substances in the plants (Moreno et al., 2005; Zhu et al., 2010). In contrast, an inducible promoter enables transferred exogenous genes to be expressed in specific tissues or at specific stages of development; thus, expression of the exogenous gene would be less likely to interfere with plant growth and development but would allow host cells to respond to specific environmental signals (Castresana et al., 1990; Chang et al., 2009). On this basis, an effective strategy for engineering disease resistance into plants is to identify and transfer appropriate inducible promoters into the plants and to confirm that the promoter supports the desired pattern of expression of the exogenous gene (Zuo and Chua, 2000).

Pathogen-induced promoters have been identified in the upstream regulatory sequences of some defense response genes. For example, the promoter for the beta-1,3-glucohexaose glycosidase gene in wild tobacco is induced by the bacterial pathogens Pseudomonas syringae and Erwinia carotovora (Castresana et al., 1990). In Arabidopsis, the promoter for the acid chitinase gene is induced by the fungal pathogen Rhizoctonia solani; the promoter is also induced by the fungal pathogen Alternaria solani in transgenic tomato (Samac and Shah, 1991). Similarly, the promoter for the osmotic regulation protein osmotin in potato can be induced by a chemical inducer and by the fungal pathogen Phytophthora infestans (Gong and Li, 2000; Pontier et al., 2001). 
In plants, defense responses can be induced by pathogen elicitors, i.e., recognition of the pathogen elicitor by the plant may cause the plant to produce proteins that resist infection. Elicitors are also experimentally useful because they can be used in place of pathogens to study promoter induction ( $\mathrm{Li}$ et al., 2007). Promoters differ in many ways including regulatory element sequence, induction drive activity, and inductive response to the external environment. Therefore, increasing the expression of a defense-related gene depends on identifying and understanding the characteristics of its specific promoter.

The chitinase gene has been isolated and cloned from peanut (GenBank accession No. HQ439775). In this study, we sought to isolate the upstream promoter sequences of the chitinase gene, to predict the function of this promoter, and to confirm the key cis-regulatory elements. This information will provide the basis for induced high-level expression of the endogenous peanut chitinase gene by an elicitor.

\section{MATERIAL AND METHODS}

\section{Plants and growing conditions}

The peanut (Arachis hypogaea L.) variety Xiyangsheng and onion bulbs (Allium cepa L.) were used in this study. Peanut seeds were sown in autoclaved soil in $10 \mathrm{~cm}$ diameter clay pots (one plant per pot) and were kept in a greenhouse in an incubator at $25^{\circ} \mathrm{C}$ and $60 \%$ relative humidity, under $13 \mathrm{~h}$ light $/ 11 \mathrm{~h}$ dark conditions. The same conditions were used for all experiments. Onions bulbs were obtained from the Plant Physiology Laboratory of Qingdao Agricultural University.

\section{Treatment of peanut seedlings with SA to induce chitinase expression}

Twenty-day-old peanut seedlings were sprayed with a solution of $1.5 \mathrm{mM} \mathrm{SA}$ and $0.1 \%$ Tween-20, pH 7.0, or with $0.1 \%$ Tween-20 alone (control). The SA or control solution was sprayed on both sides of each leaf until the entire leaf surface was wet. After 0, 12, 24, 36, 48, or 72 h, 3 - 4 leaves were collected, quickly frozen in liquid nitrogen, and stored at $-80^{\circ} \mathrm{C}$ until required.

\section{Extraction of total RNA and assessment of chitinase gene expression}

Total RNA was isolated from the frozen peanut leaves and then reverse-transcribed into cDNA. Reverse transcription was performed using an ABI 7500 FAST Real-Time PCR System. The primers Actin- $F$ and Actin- $R$ were used to amplify the peanut reference gene Ah-Actin, and the primers $A h-C h i-F$ and $A h-C h i-R$ were used to amplify the peanut chitinase gene $(A h-C h i)$. The sequences of all primers used in this study are listed in Table 1. The amplification protocol was as follows: $95^{\circ} \mathrm{C}$ for $2 \mathrm{~min}$; followed by 40 cycles of $95^{\circ} \mathrm{C}$ for $10 \mathrm{~s}$ and $60^{\circ} \mathrm{C}$ for $40 \mathrm{~s}$; and then a slow increase to $95^{\circ} \mathrm{C}$. A dissociation curve was then prepared. Each reaction was repeated. The relative level of expression of the target gene was calculated according to the $2^{-(\Delta \Delta \mathrm{Ct})}$ method of Livak and Schmittgen (2002).

\section{Cloning the full-length promoter of the peanut chitinase gene}

Three nested specific primers (SP1, SP2, and SP3) were designed using the 5'-end sequence of peanut chitinase cDNA (GenBank accession No. HQ439775). The upstream promoter 
sequence, termed here Ah-Chi-Pro, was amplified by TAIL-PCR using Xiyangsheng genomic DNA as template. Two other primers, Chi-F and $C h i-R$, were designed using the sequence of the promoter Ah-Chi-Pro; their PCR amplification product is termed here Ah-Chi-P.

Table 1. Names and sequences of primers used in this study.

\begin{tabular}{ll}
\hline Name & Sequence(from $5^{\prime}$ to 3') $^{\prime}$ \\
\hline Actin-F & GTGGCCGTACAACTGGTATYGT \\
Actin-R & ATGGATGGCTGGAAGAGAACT \\
Ah-Chi-F & GAGACAACAGGGAGGAACGA \\
Ah-Chi-R & ATCTGCCTTTATAGCTTGTCCA \\
SP1 & ACCTGTTGTCTCGTGTGATGTTTGG \\
SP2 & TGACGTCATCACCGGTTGTTCC \\
SP3 & GCTTCAGGAATTCATTATAGAGAGGC \\
Chi-F & GGATCCAGCATTTCCCTACTTTACGTATTC \\
Chi-R $R$ & CCATGGCTGTTTTGAGTTTGGGATGTAC \\
Chi- $P_{1}$ & GGATCCATGATAGTTCTGTCTTAG \\
Chi- $P_{2}$ & GGATCCGAGCACCATTTGTTAGAACGCTT \\
Chi- $P_{3}$ & GGATCCTGAGAGCAAACTTATTCTTCTT \\
Chi- $P_{4}$ & GGATCCGTAGACTCAGAAATCGTTGGGGAT \\
Chi-P $P_{5}$ & GGATCCTGCTGACATAATAATAGACATTG \\
\hline
\end{tabular}

GGATCC is the BamHI restriction enzyme cutting site, and CCATGG is the Ncol restriction enzyme cutting site.

\section{Function prediction of the peanut chitinase gene promoter}

The relevant cis-elements within $A h-C h i-P$ were predicted using the plant cis-acting regulatory element databases PLACE (http://www.dna.affrc.go.jp/PLACE/) (Higo et al. 1999) and (Links ok) plantCARE (http://bioinformatics.psb.ugent.be/webtools/plantcare/html/) (Lescot et al., 2001).

\section{Cloning a series of 5 -deleted sequences of the peanut chitinase gene promoter}

According to the predicted cis-acting elements within $A h-C h i-P$, five forward primers, Chi- $P_{1}$ to $C h i-P_{5}$, and one reverse primer, Chi-R, were designed; each primer includes a BamHI restriction site (Table 1). The primers were used to amplify 5'-deleted sequences of $A h-C h i-P$. The PCR amplification products were sequenced. The five promoters with 5'-deleted sequences were named $P_{1}$ to $P_{5}$.

\section{Construction of plant expression vectors}

35S promoter of $p C A M B I A 1301-x y I A$ had been removed by digestion with both BamHI and $\mathrm{Ncol}$, and further substituted by the full-length promoter $(A h-C h i-P)$ and the five deleted promoters $\left(P_{1}\right.$ to $\left.P_{5}\right)$ respectively. The derived combination plasmids were named pCAMBIA1301-xylA-Chi-P to $p C A M B I A 1301-x y I A-C h i-P_{5}$ and were transferred into Agrobacterium EHA105.

\section{GUS transient expression in transformed onion epidermal cells}

Fresh onion bulbs were cut into $0.25-\mathrm{cm}^{2}$ pieces and pre-cultured in $\mathrm{MSB}_{5}$ medium in the dark for $24 \mathrm{~h}$; the onion pieces were then immersed in a solution containing Agrobacterium EHA105 and a plasmid ( $p C A M B I A 1301-x y I A-C h i-P$ to $p C A M B I A 1301-x y I A-C h i-P_{5}$ ) for 15 min, then cultured in the dark for 3 days. Transformed onion epidermal cells and control cells were treated with $5.0 \mathrm{mM} \mathrm{SA}$ or distilled water for $84 \mathrm{~h}$ and then stained for GUS activity by incubating overnight 
in X-gluc, $0.1 \mathrm{mM}$ phosphate buffer, pH 7.0, $1 \mathrm{mM}$ EDTA, $5 \mathrm{mM}$ potassium ferrocyanide, Triton $\mathrm{X}-100$, and $\mathrm{N}, \mathrm{N}$-dimethylformamide at $37^{\circ} \mathrm{C}$, followed by decolorizing in $70 \%$ ethanol. GUS enzyme activity in transformed onion epidermal cells was detected as previously described (Ma et al. 2010).

\section{Analysis of GUS expression in transgenic peanuts}

Plasmids $p C A M B I A 1301-x y I A-C h i-P$ to $p C A M B I A 1301-x y I A-C h i-P_{5}$, were separately transformed into cotyledon explants of the peanut variety Huayu-23. Transformed plants were selected on SEM culture medium containing $20 \mathrm{~g} / \mathrm{L}$ xylose and $10 \mathrm{~g} / \mathrm{L}$ sucrose as described previously (Ding et al., 2012).

PCR amplification was performed using the primers GUS- $F$ and GUS-R and the genomic DNA of the transformed peanut plants as template. The amplification protocol was as follows: $94^{\circ} \mathrm{C}$ for $5 \mathrm{~min} ; 32$ cycles of $94^{\circ} \mathrm{C}$ for $50 \mathrm{~s}, 56^{\circ} \mathrm{C}$ for $50 \mathrm{~s}$, and $72^{\circ} \mathrm{C}$ for $40 \mathrm{~s}$; and a final extension at $72^{\circ} \mathrm{C}$ for $10 \mathrm{~min}$. The amplification products were separated by $1 \%$ agarose gel electrophoresis.

Transformed plants and control plants were treated with $5.0 \mathrm{mM} \mathrm{SA}$ for $72 \mathrm{~h}$. The primers Ah-Actin- $F$ and Ah-Actin- $R$ were used to amplify the Actin reference gene, and the primers GUS- $F$ and GUS-R were used to amplify the GUS gene. Real-time fluorescent quantitative PCR was performed as described above.

\section{RESULTS}

\section{Expression level of peanut chitinase gene after SA induction}

After treatment with SA, the level of $A h$-Chi mRNA in peanut leaves increased and, at $72 \mathrm{~h}$ after treatment, was more than 4 times greater than in water treated controls, getting a very significant difference $(P<0.01)$ (Figure 1). Thus, the promoter of the peanut chitinase gene is SA-inducible.

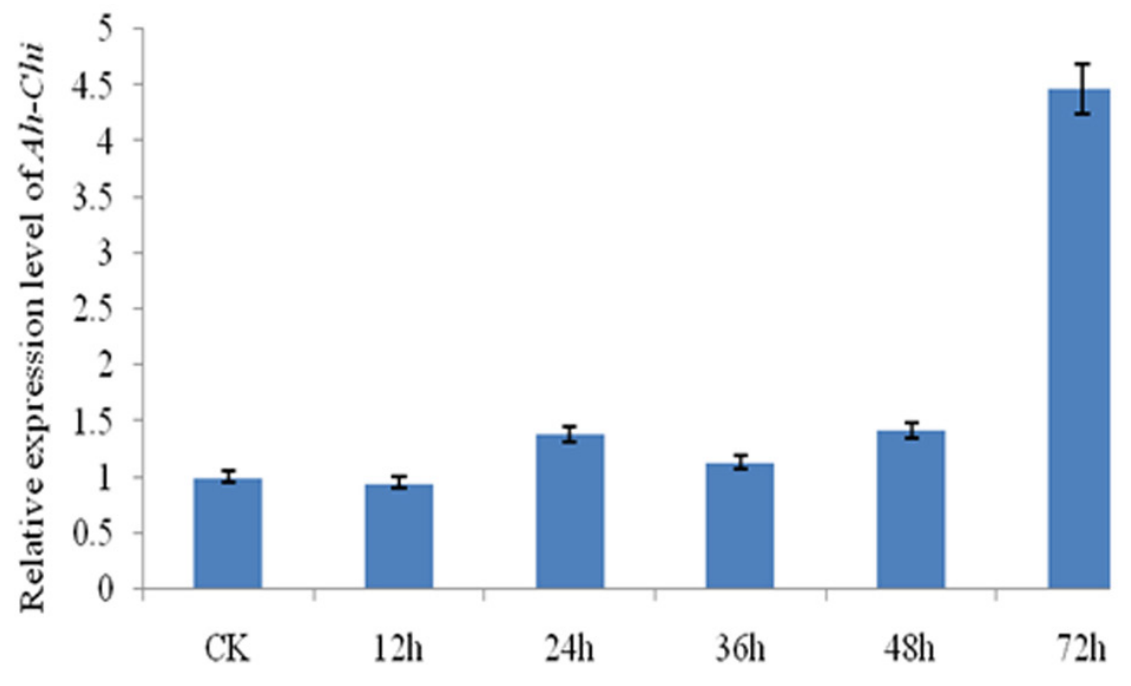

Hours after SA treatment

Figure 1. mRNA expression level of Ah-Chi in peanut after treatment with 1.5 mM SA. Data are reported as means + SEM. 


\section{Cloning of the promoter of the peanut chitinase gene}

TAIL-PCR amplification was conducted using a random combination of the three nested specific primers, SP1 to SP3, with one of the four random primers, AP1 to AP4. A single $1710 \mathrm{bp}$ specific band was obtained when $S P 1$ to $S P 3$ were paired with $A P 3$ in the third round of amplification; no specific bands were obtained if $S P 1$ to $S P 3$ were paired with $A P 1, A P 2$, or $A P 4$ (Figure 2a). As the sequence of the $1710 \mathrm{bp}$ band matched that of the $5^{5}$-end of the peanut chitinase gene, the amplification product was considered to be the upstream promoter sequence for the peanut chitinase gene and was named Ah-Chi-Pro. A 1650 bp band was generated using primers Chi-F and Chi-R, and named $A h-C h i-P$. This amplification product was inserted into the $p M D 18-T$ vector to obtain the recombinant plasmid $P M D 18-T-A h-C h i-P$; construction of the plasmid was verified by PCR and double-digestion with $\mathrm{BamHI}$ and $\mathrm{Ncol}$, which produced the $1650 \mathrm{bp}$ construct (Figure 2b,c).
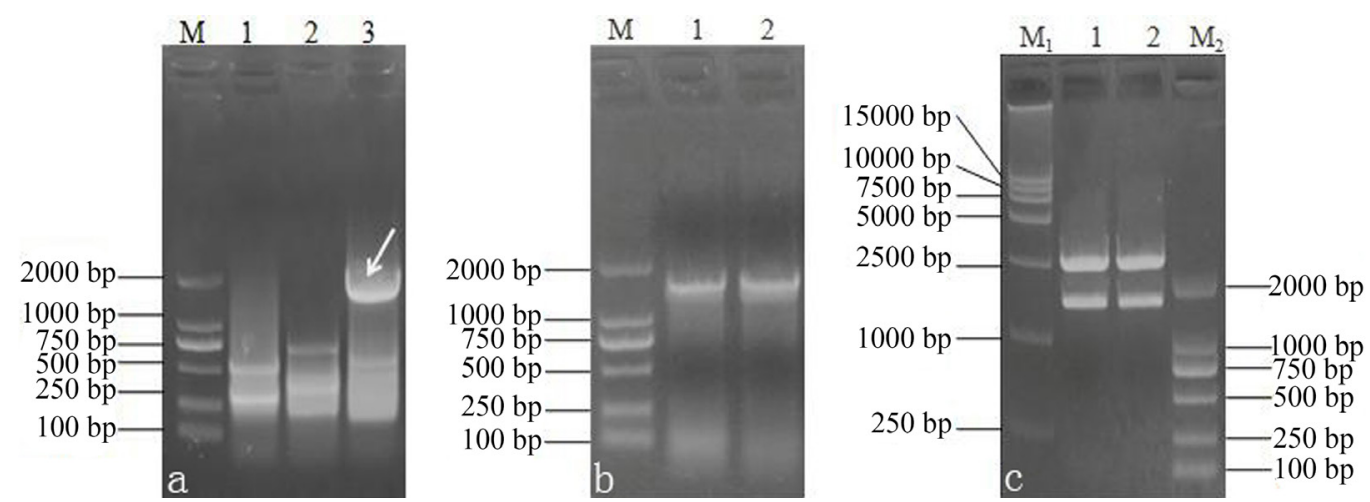

Figure 2. TAIL-PCR amplification of Ah-Chi-P and confirmation of recombinant plasmids pMD18-T-Ah-Chi-P. a. TAILPCR amplification by primer-pair SP1/AP3, SP2/AP3, and SP3/AP3 in three steps. M: DL2000; 1: product amplified by SP1 and AP3 in first step; 2: product amplified by SP2 and AP3 in second step; 3: product amplified by SP3 and AP3 in third step. b. Confirmation of recombinant plasmids by PCR. M: DL2000; 1, 2: product amplified by primers Chi-F and Chi-R. c. Confirmation of recombinant plasmids by BamHI and Ncol digestion. M1: DL15000; 1, 2: Products digested by BamHI and Ncol; M2: DL2000.

\section{Analysis of the predicted function of the peanut chitinase gene promoter}

Online prediction and analysis using PLACE and PlantCARE databases showed that the $A h$-Chi-P promoter region contained approximately 90 regulatory elements distributed across 401 sites. These elements included typical regulatory elements such as a CAAT-box and a TATAbox. Also predicted were regulatory elements related to pathogen-induced reactions: the GT1motif (GAAAAA), TGTCA, TTGCA, and TGAC, which play an important role in pathogen-induced gene expression (Park et al., 2004); AS-1 (TGACG), which is mainly involved in SA-induced gene expression (Redman et al., 2002); and W-box, WB-box (TTTGACY), and EIRE (TTCGACC), which respond to elicitors (Laloi et al., 2004). Other cis-acting elements found in $A h-C h i-P$ included WAACCA and YAACKG, which are related to drought-resistance, and TACGTGTC, ACGTGKC, and TACGTGTC, which are related to ABA-induced reactions (Lu et al., 2009; Graeber et al., 2010). The major elements responsible for pathogen and SA responsiveness were present in different sites of the promoter (Table 2 and Figure 3 ). 
Table 2. Primary cis-acting elements which might be relevant to disease resistance and SA induction.

\begin{tabular}{|c|c|c|c|c|c|c|}
\hline $\begin{array}{l}\text { sequence range } \\
\text { concerned elements }\end{array}$ & $\begin{array}{c}\text { P-P1 } \\
1641-1513\end{array}$ & $\begin{array}{c}\mathrm{P} 1-\mathrm{P} 2 \\
1512-1384\end{array}$ & $\begin{array}{c}\text { P2-P3 } \\
\text { 1383-995 }\end{array}$ & $\begin{array}{c}\text { P3-P4 } \\
994-618\end{array}$ & $\begin{array}{c}\text { P4-P5 } \\
617-236\end{array}$ & $\begin{array}{c}\text { P5 } \\
235-31\end{array}$ \\
\hline TGACG (AS-1) & 0 & 0 & 1 & 0 & 0 & 0 \\
\hline TGTCA & 1 & 2 & 0 & 1 & 1 & 1 \\
\hline GRWAAW & 2 & 2 & 3 & 6 & 2 & 4 \\
\hline GAAAAA & 0 & 0 & 1 & 2 & 1 & 2 \\
\hline TTTGACY (WB BOX) & 0 & 0 & 1 & 0 & 0 & 0 \\
\hline TTGAC (W BOX) & 0 & 1 & 1 & 1 & 2 & 1 \\
\hline TGACT (W BOX) & 0 & 0 & 1 & 0 & 2 & 1 \\
\hline TGACY (W BOX) & 0 & 0 & 1 & 0 & 2 & 2 \\
\hline TGAC (WRKY710S) & 1 & 2 & 2 & 1 & 3 & 3 \\
\hline Total & 4 & 7 & 11 & 11 & 13 & 4 \\
\hline
\end{tabular}

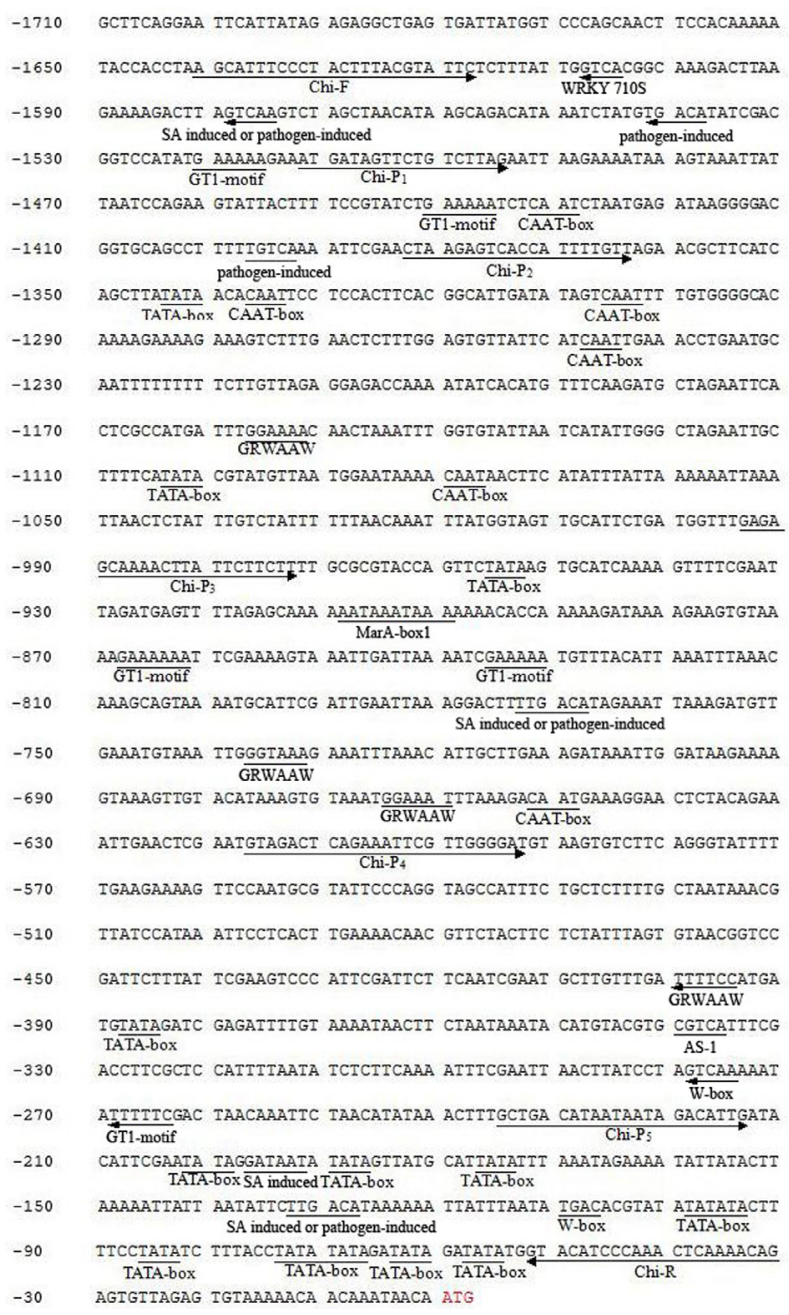

Figure 3. Function prediction for Ah-Chi-Pro sequences by databases PLACE and plantCARE. Long arrows indicate the orientation of the primer sequences. Short left-pointing arrows show putative cis-acting elements in the complementary chain. Underlined sequences indicate cis-elements in the positive chain. 


\section{Cloning of a series of 5'-deleted promoter sequences and expression vector construction}

Plasmids $p C A M B I A 1301-x y I A-C h i-P$ to $p C A M B I A 1301-x y I A-C h i-P_{5}$ were confirmed by PCR amplification and double-digestion with BamHI and $\mathrm{Ncol}$, and corresponding target bands were obtained (Figure $4 a, b)$.

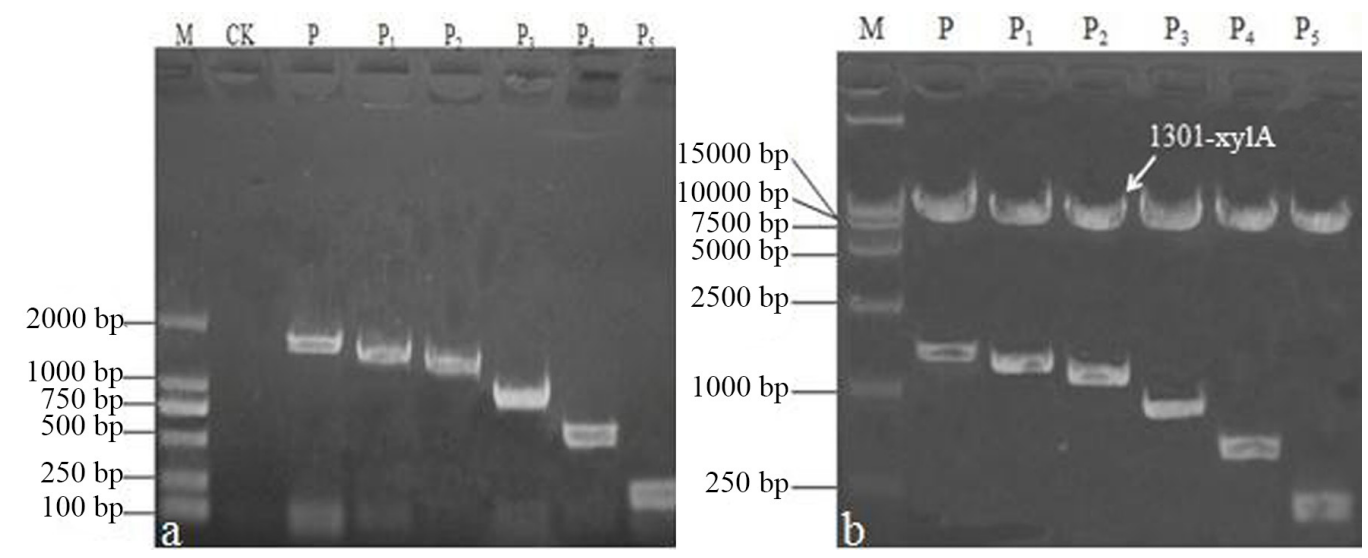

Figure 4. Confirmation of the recombinant plasmid $p C A M B I A 1301-A h-C h i-P$ by PCR (a) and BamHI and Ncol digestion (b). a. M: DL2000; CK indicates the control that lacks a DNA template; P (full-length promoter), P1,P2, P3, P4, and P5 (serially deleted primers) are the PCR products amplified from $p C A M B I A 1301-x y / A-C h i-P, P 1, P 2, P 3$, $P 4$, and $P 5$. b. M: DL15000; $P, P 1, P 2, P 3, P 4$, and $P 5$ are BamHl and Ncol double-digestion products of $p C A M B I A 1301-x y / A-C h i-P$, $P 1, P 2, P 3, P 4$, and $P 5$.

\section{GUS staining of transformed onion epidermal cells}

In the absence of SA induction, non-transformed onion epidermal cells did not show GUS staining (Figure 5a) whereas onion epidermal cells transformed with the CaMV35S promoter (positive control) did show staining (Figure $5 \mathrm{~b}$ ). Onion epidermal cells transformed by pCAMBIA1301-Ah-Chi-P showed light staining without SA induction (Fig. 5c), but displayed deeper staining after SA induction (Fig. 5d). Thus, Ah-Chi-P is a promoter that can be induced by SA. Onion epidermal cells transformed with the 5 '-deleted promoters $P_{1}$ to $P_{5}$ were also stained after $\mathrm{SA}$ induction (Figure $5 \mathrm{e}-\mathrm{i}$ ). The intensity of staining varied depending on the sequences deleted, indicating differences in the levels of activity driven by promoters $P_{1}$ to $P_{5}$.

\section{Quantitative analysis of GUS activity in onion epidermal cells}

GUS activity in onion epidermal cells transformed with the CaMV35S promoter was similar with or without SA treatment (Figure 6), indicating that the 35 S promoter cannot be induced by exogenous SA. In contrast, GUS activity in cells transformed with $\mathrm{P}$ to $\mathrm{P}_{5}$ promoters was higher after SA treatment than in its absence, indicating that the $P$ to $P_{5}$ promoters could be induced by exogenous SA. GUS activity after SA induction was especially high in cells transformed with $\mathrm{P}_{2}$ and $P_{3}$. The results suggested that there might be positive regulatory elements within $P_{2}$ and $P_{3}$, and also that there might be negative regulatory elements between the $\mathrm{P}$ and $\mathrm{P}_{2}$ sequences. 


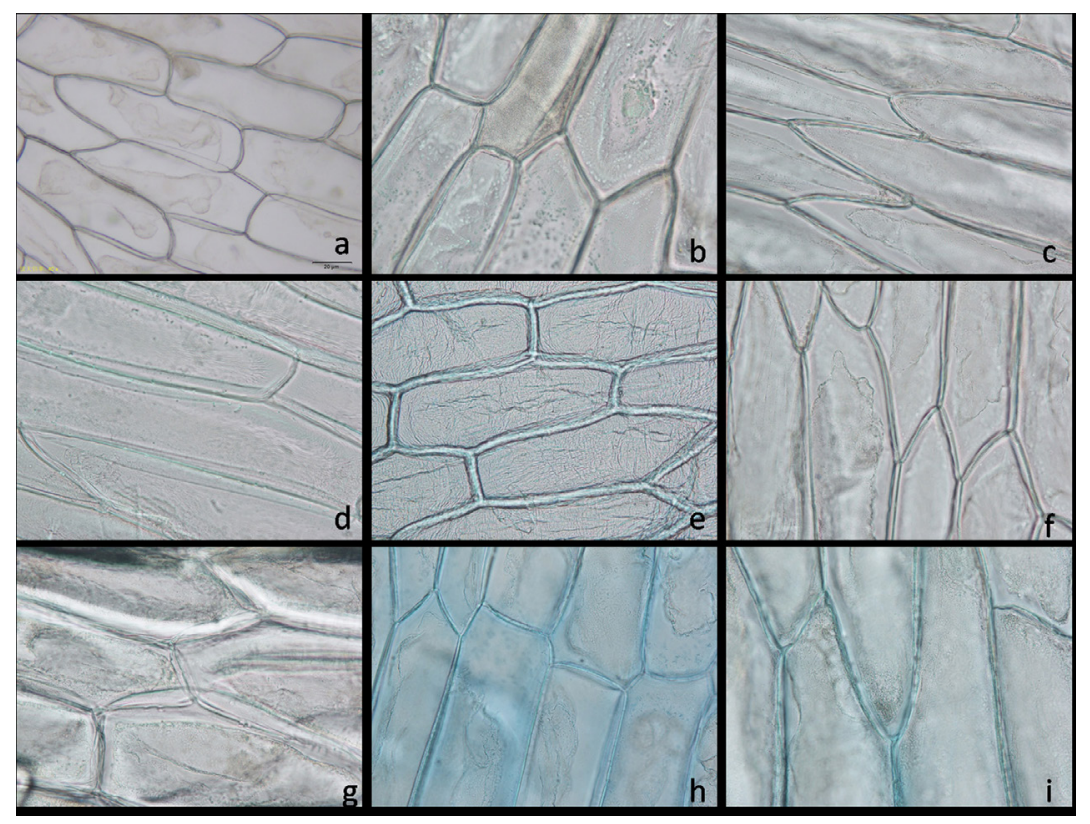

Figure 5. GUS staining of transformed onion epidermal cells. a.-c. Cells not induced by SA. d.-i. Cells induced by 5.0 mM SA for 84 h. a. Negative control: non-transformed cells. b.-i. Transformed cells driven by a positive control: $35 \mathrm{~S}$ (b), Ah-Chi-P (c-d), Ah-Chi-P ${ }_{1}(\mathbf{e}), A h-C h i-P_{2}(\mathbf{f}), A h-C h i-P_{3}(\mathbf{g}), A h-C h i-P_{4}(\mathbf{h})$, and Ah-Chi-P ${ }_{5}(\mathbf{i})$.

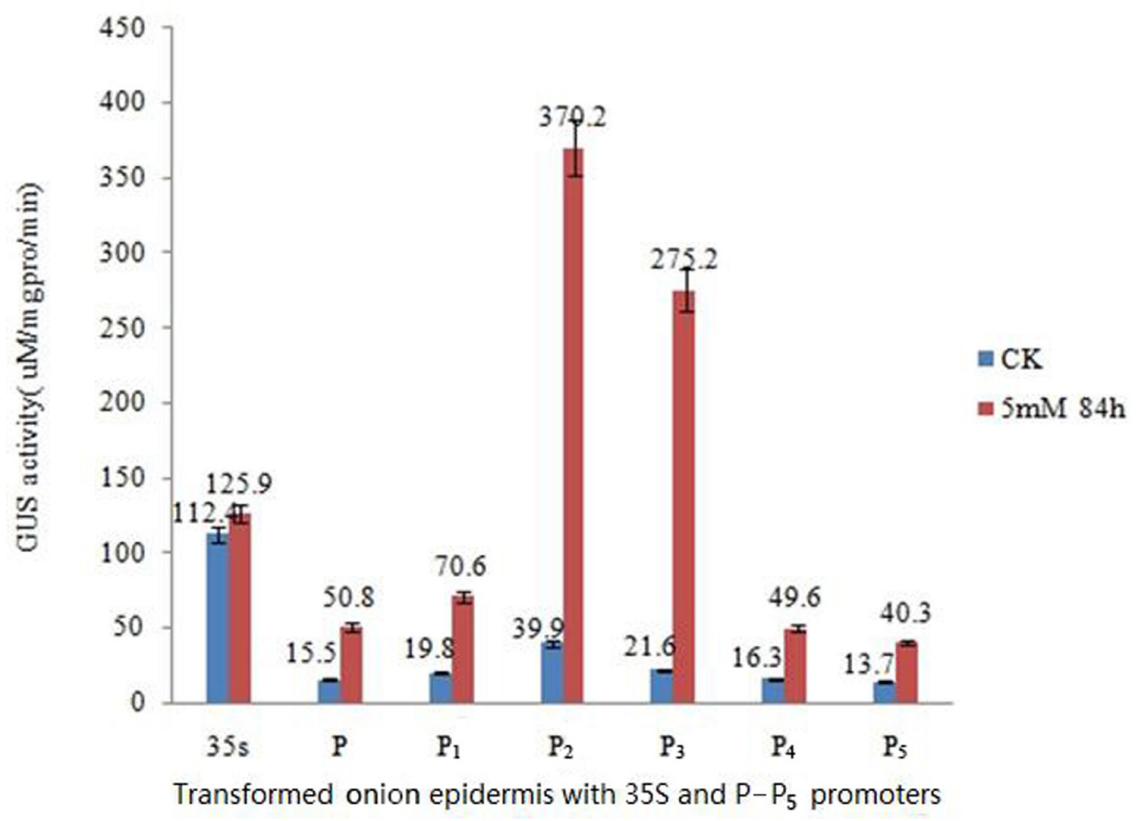

Figure 6. GUS enzyme activity in transformed onion epidermal cells after treatment for $84 \mathrm{~h}$ with water (blue bars) or $5 \mathrm{mM}$ SA (red bars). Data are reported are means + SEM. 


\section{GUS expression in transgenic peanuts carrying the $P$ to $P_{5}$ promoters}

The generation of the $T_{0}$ transgenic peanuts was confirmed by PCR using the primers GUS- $F$ and GUS-R, getting a 410 bp target fragment. In regenerated plants screened with xylose, $81 \%$ were confirmed to be transgenic. GUS mRNA levels in transgenic peanuts transformed with the CaMV35S promoter were similar with or without SA treatment (Figure 7). GUS mRNA levels in transgenic peanuts transformed with promoter $P$ to $P_{5}$ were greater after $S A$ treatment than in its absence. As was the case for GUS activity in transgenic onion epidermal cells, GUS mRNA levels increased sharply after SA treatment of peanuts transformed with the $P_{2}$ and $P_{3}$ promoters but increased much less in peanuts transformed with the $\mathrm{P}$ and $\mathrm{P}_{1}$ promoters. Again the evidence indicates the presence of positive regulatory elements in the $\mathrm{P}_{2}$ and $\mathrm{P}_{3}$ promoters that are responsive to $\mathrm{SA}$ induction, and also the presence of negative regulatory elements in $\mathrm{P}$ and $\mathrm{P}_{1}$ promoters.

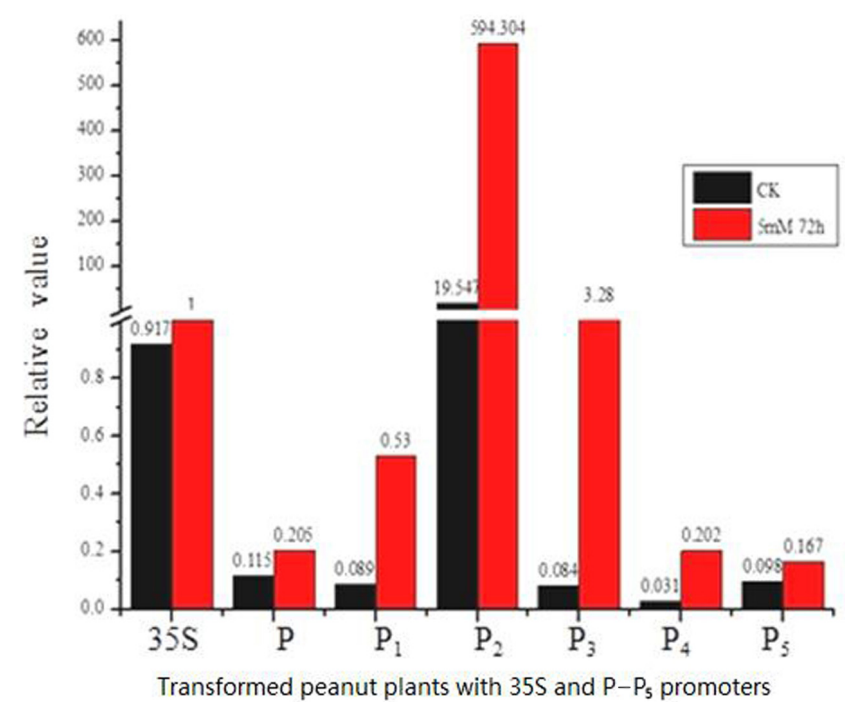

Figure 7. GUS mRNA levels in transformed peanut plants after treatment for $84 \mathrm{~h}$ with water (black bars) or $5 \mathrm{mM} \mathrm{SA}$ (red bars).

\section{DISCUSSION}

Promoters, which are located upstream of structural genes and have a binding site for RNA polymerase, regulate gene transcription by recognizing and binding to transcription factors. The processes involved in regulating eukaryotic gene expression are complex, and promoter-mediated control at the transcription level is an important aspect of the overall mechanism. Elucidating how promoters regulate transcription requires information from many sources, for example, cloning, confirmation of promoter function, and analysis of the interactions between promoter and transcription factor (Mu et al. 2013).

In this study, we cloned the upstream promoter sequence of the peanut chitinase gene using TAIL-PCR, and a series of 5'-deletion promoter sequences were obtained by PCR amplification. Transcription initiation by the full-length promoter or these 5'-deletion promoter sequences was studied using GUS enzyme activity in transformed onion epidermal cells and GUS mRNA levels 
in transformed peanut plants. Out results indicated that the promoter of the peanut chitinase gene responded to treatment with SA and that GUS enzyme activity and GUS mRNA levels after SA induction differed depending on the promoter sequence used in the assay.

Overall, our results suggested that the promoter of the peanut chitinase gene contains both positive and negative regulatory mechanisms. A similar conclusion was made with respect to the soybean GmDREB3 promoter and the endosperm-specific ALP type-B gene promoter (Sun et al. 2008). Regarding regulation of expression of the peanut chitinase gene, the negative regulatory elements in the promoter possibly interfere with interactions between transcription factors and positive regulatory elements; this antagonism might affect expression of downstream genes. It is also possible that the positive and negative regulatory elements jointly affect the formation of a transcription initiation complex, thus affecting expression of downstream genes.

In transgenic peanuts with different lengths of promoter sequence, SA treatment increased GUS expression to a variable extent depending on the promoter present. The same effect was found for GUS enzyme activity in transgenic onion epidermal cells. The $P_{2}$ and $P_{3}$ promoters showed the strongest responses to SA, suggesting that they might contain key cis-elements responsive to SA induction. Predictive analysis of promoter structure using PLACE and PLANTcare databases indicated that the full-length promoter $P$ contains 90 types of regulatory elements at 401 different sites: 32 regulatory elements were located between $P$ and $P_{1}, 35$ between $P_{1}$ and $P_{2}, 92$ between $\mathrm{P}_{2}$ and $\mathrm{P}_{3}, 98$ between $\mathrm{P}_{3}$ and $\mathrm{P}_{4}, 84$ between $\mathrm{P}_{4}$ and $\mathrm{P}_{5}$, and 60 within $\mathrm{P}_{5}$. These include typical regulatory elements such as CAAT and TATA boxes, a TATTCT box that is responsive to light, a tissue-specific expression element TGHAAARK, an ACGTG responsive to dehydration and dark, a TACGTGTC responsive to ABA, a TGACG responsive to jasmonic acid, SAR-binding domains MarAbox1 (AATAAAYAAA), MarTbox (TTWTWTTWTT), and 5'-UTR (Py-rich) (Lu et al. 2009; Graeber et al. 2010). Also detected were elements involved in disease resistance and SA induction: the disease-resistance elements TGTCA, GAAAAA (GT1-motif), and TGAC; the SAinduction elements TGACG (AS-1 element) and GRWAAW; W-Box elements (TTGAC, TGACT, TGACY) responsive to both pathogen and SA; and a TTTGACY element (WB-box) responsive to an elicitor (Somssich, 1994; Zhen et al., 2000; Kundu et al., 2011; Maita et al., 2015). The various GUS mRNA levels generated by the different promoters (Figures 6 and 7) lead us to speculate that the high level of expression associated with $P_{2}$ might be related to its AS-1 element. GUS mRNA level was low with $P_{3}, P_{4}$ and $P_{5}$, which lacks the AS-1 element. This indicates that the AS-1 element plays a key role in the response of the chitinase promoter to SA. A GRWAAW element was detected within all of the $P_{1 \text { to }} P_{5}$ promoters and might be another element responsive to SA. $P_{3}$ contained 12 GRWAAW elements, more than in the $P_{4}$ and $P_{5}$ promoters. It is possible that the higher level of GUS expression driven by $\mathrm{P}_{3}$ compared to $\mathrm{P}_{4}$ and $\mathrm{P}_{5}$ promoters is also associated with its high number of GRWAAW elements. The WB-Box and W-Box are considered AS-1-like elements, as they contain a TGAC sequence as their core motif. Six WB-Box and W-Box elements were present within $\mathrm{P}_{2}-\mathrm{P}_{3}$, and they might contribute to the increased transcriptional activity driven by $P_{2}$. The W-Box can specifically bind with transcription factors of the WRKY family, which regulate the expression of PR-proteins after induction by exogenous SA (Yu et al. 2001). $P$ and $P_{1}$ showed a much weaker response to $S A$ induction than $P_{2}$, indicating that $P$ and $P_{1}$ might contain negative regulatory elements. In addition to the positive GRWAAW and W-Box elements, $\mathrm{P}$ and $\mathrm{P}_{1}$ also contain a GT1-motif and TGTCA elements. The GT-1 light-responsive element acts as a negative regulatory element within the GalUR promoter in strawberry (Agius et al., 2005). Possibly, it also acts within $P-P_{1}$ and $P_{1}-P_{2}$ as a negative regulatory element for chitinase expression in peanut. TGTCA may be another negative regulatory element. Thus, in addition to the presence of positive 
elements, the high promoter activity of $\mathrm{P}_{2}$ might be related to the absence of a TGTCA element.

In summary, the promoter region of the peanut chitinase gene contains a series of important regulatory elements. CAAT and TATA are indispensable for gene transcription and play a key role in transcription initiation. The AS-1, W-box, and GRWAAW elements might have a positive regulatory effect and be involved in the response to SA. The GT1-motif and TGTCA might be negative regulatory elements. However, as there are so many regulatory elements within each of the promoters, it is difficult to identify unambiguously the exact function of each element. Clarifying these functions will require additional investigations using single point mutations and yeast hybrid technology.

\section{Conflicts of interest}

The authors declare no conflict of interest.

\section{ACKNOWLEDGMENTS}

Research financially supported by the National Natural Science Foundation of the P. R. China (\#31471542 and \#31301356), Shandong Province Science and Technology Project (\#2014GNC110002) and Shandong Province Germplasm Innovation and Utilization Project. We thank Prof. Bruce Jaffee for critical reading of the manuscript.

\section{REFERENCES}

Agius F, Amaya I, Botella MA and Valpuesta V (2005). Functional analysis of homologous and heterologous promoters in strawberry fruits using transient expression. J. Exp. Bot. 56: 37-46.

Castresana C, de Carvalho F, Gheysen G, Habets M, et al. (1990). Tissue-specific and pathogen-induced regulation of a Nicotiana lumbaginifolia $\beta$-1,3-glucanase gene. Plant Cell 2: 1131-1143.

Chang JQ, Wang XL, Yang Y, Chen Y, et al. (2009). Cloning of cold-induced promoter CBF 3 from Arabidopsis thaliana and its activity detection in transgenic tobacco. Biotechnology 19: 5-7.

Ding X, Sui JM, Wang JS and Qiao LX (2012). The genetic transformation of peanut using xylose isomerase gene as a selection marker. J. Nucl. Agr. Sci. 26: 444-448.

Gong M and Li X (2000). Reporter genes. Chem. Life 20: 126-128.

Graeber K, Linkies A, Müller K, Wunchova A, et al. (2010). Cross-species approaches to seed dormancy and germination: conservation and biodiversity of ABA-regulated mechanisms and the Brassicaceae DOG1 genes. Plant Mol. Biol. 3: 67-87.

Higo K, Ugawa Y, Iwamoto M and Korenaga T (1999). Plant cis-acting regulatory DNA elements (PLACE) database: 1999. Nucleic Acids Res. 27: 297-300.

Jia YC, Wang L, Chen Q, Li LG, et al. (2011). Establishment of genetic transformation system of peanut cotyledon node explants. Sci. Technol. Eng. 11: 3142-3146.

Kellmann JW, Kleinow T, Engelhardt K, Philipp C, et al. (1996). Characterization of two class II chitinase genes from peanut and expression studies in transgenic tobacco plants. Plant Mol. Biol. 30: 351-358.

Kundu S, Chakraborty D and Pal A (2011). Proteomic analysis of salicylic acid induced resistance to mungbean yellow mosaic India virus in Vigna mungo. J. Prot. 74: 337-349.

Laloi C, Mestres-Ortega D, Marco Y, Meyer Y, et al. (2004). The Arabidopsis cytosolic thioredoxin h5 gene induction by oxidative stress and its W-box-mediated response to pathogen elicitor. Plant Physiol. 134: 1006-1016.

Lescot M, Déhais P, Thijs G, Marchal K, et al. (2001). PlantCARE, a database of plant cis-acting regulatory elements and a portal to tools for in silico analysis of promoter sequences. Nucleic Acids Res. 30: 325-327.

Li N, Fan SJ and Zhang ZY (2007). Progress in plant promoters related to disease resistance. J. Plant Genet. Resour. 8: 234-239.

Liu F, Li CJ, Xu TT, Shan SH, et al. (2007). Main methods and advances of the research on peanut genetic transformation. Lett. Biotechnol. 18: 719-722.

Livak KJ and Schmittgen TD (2002). Analysis of relative gene expression data using real-time quantitative PCR and the 2(-Delta Delta C (T)) Method. Methods 25: 402-408.

Lu GJ, Gao CX, Zheng XN and Han B (2009). Identification of OsbZIP72 as a positive regulator of ABA response and drought tolerance in rice. Planta 229: 605-615. 
Ma L, Mei XH, Xu WT, Luo YB, et al. (2010). Analyses of functional region of maize In5-2 promoter in transient expression system of onion. J. Agr. Biotechnol. 18: 1073-1078.

Maiti S, Patro S, Pal A and Dey N (2015). Identification of a novel salicylic acid inducible endogenous plant promoter regulating expression of CYR1, a CC-NB-LRR type candidate disease resistance gene in Vigna mungo. Plant Cell Tiss. Org. 120: 489-505.

Moreno AB, Penas G, Rufat M, Bravo JM, et al. (2005). Pathogen-induced production of the antifungal AFP protein from Aspergillus giganteus confers resistance to the blast fungus Magnaporthe grisea in transgenic rice. Mol. Plant Microbe Interact. 18: 960-972.

Mu SL, Cai JS, Yan Y, Qiu AL, et al. (2013). Cloning of Pi-ta promoter and its function analysis in rice. J. Nucl. Agr. Sci. 27: 1803-1808. (in Chinese)

Park HC, Kim ML, Kang YH, Jeon JM, et al. (2004). Pathogen- and NaCl-induced expression of the SCaM-4 promoter is mediated in part by a GT-1 box that interacts with a GT-1-like transcription factor. Plant Physiol. 135: 2150-2161.

Pontier D, Balague C, Bezombes-Marion I, Tronchet M, et al. (2001). Identification of a novel pathogen-responsive element in the promoter of the tobacco gene HSR203J, a molecular marker of the hypersensitive response. Plant J. 26: 495-507.

Qu MJ, Huang ZL, Ju Q, Liu K, et al. (2008). The research on inducement of peanut chitinase activity by $P$. arachidicola Marass and A. flavus. J. Peanut. Sci. 37: 1-6.

Redman J, Whitcraft J, Johnson C and Arias J (2002). Abiotic and biotic stress differentially stimulate as-1 element activity in Arabidopsis. Plant Cell Rep. 21: 180-185.

Samac DA and Shah DM (1991). Developmental and pathogen-induced activation of the Arabidopsis acidic chitinase promoter. Plant Cell 3: 1063-1072.

Somssich IE (1994). Regulatory elements governing pathogenesis-related (PR) gene expression. In: Results and problems in cell differentiation. Vol 20. Plant promoters and transcription factors (Nover L, eds.). Springer-Verlag, Berlin/Heidelberg, 163-179.

Sun X, Dong JH, Chen M, Xu ZS, et al. (2008). Isolation and Regulative Region Analysis of Promoter of Stress-Related Gene GmDREB3 from Soybean. Acta Agron. Sin. 34: 1475-1479. (in Chinese)

Vellicce GR, Ricci JC, Hernández L and Castagnaro AP (2006). Enhanced resistance to Botrytis cinerea mediated by the transgenic expression of the chitinase gene ch5B in strawberry. Transgenic Res. 15: 57-68.

Wang CT and Zhang JC. (2013). Peanut genetic improvement. Shanghai Science and Technology Press. (in Chinese)

Yu D, Chen C and Chen Z (2001). Evidence for an important role of WRKY DNA binding proteins in the regulation of NPR1 gene expression. Plant Cell 13: 1527-1540.

Zhen W, Chen X, Liang HB, Hu YL, et al. (2000). Enhanced late blight resistance of transgenic potato expressing glucose oxidase under the control of pathogen-inducible promoter. Chin. Sci. Bull. 45: 1982-1986.

Zhu LP, Yu Z, Zou CX and Li QL (2010). Plant stress-inducible promoters and their function. Hereditas 32: 229-234.

Zuo J and Chua NH (2000). Chemical-inducible systems for regulated expression of plant genes. Curr. Opin. Biotechnol. 11: 146-157. 